\title{
Fractographic and rheological characterizations of CF/PP-PE-copolymer composites tested in tensile
}

\author{
Paula Helena da Silva Cirilo', Clara Leal Nogueira², Jane Maria Faulstich de Paiva ${ }^{3}$, Lilia Müller Guerrini', \\ Geraldo Maurício Cândido ${ }^{1}$ and Mirabel Cerqueira Rezende, ${ }^{1, *}$
}

\author{
'Instituto de Ciência e Tecnologia, Universidade Federal de São Paulo - Unifesp, \\ São José dos Campos, SP, Brazil \\ 2Divisão de Engenharia Aeronáutica e Mecânica, Instituto Tecnológico de Aeronáutica - ITA, \\ São José dos Campos, SP, Brazil \\ ${ }^{3}$ Centro de Ciências em Gestão e Tecnologia, Universidade Federal de São Carlos - UFSCar, \\ Sorocaba, SP, Brazil \\ *mirabelcr@gmail.com
}

\begin{abstract}
This work shows the fractographic study of fractured surfaces resulted from tensile tests of thermoplastic composites based on poly(propylene-co-ethylene) (PP-PE) and modified PP-PE copolymers reinforced with continuous carbon fibers (CF). The PP-PE matrix was modified with two agents called AM1 (based on maleic anhydride) and AM2 (containing an elastomeric agent), respectively. Three different laminates - CF/PP-PE, CF/PP-PE(AM1) and CF/PP-PE(AM2) were manufactured. The best tensile strength and elastic modulus results were determined for the CF/PP-PE(AM1) laminate $(507.6 \pm 11.8 \mathrm{MPa}$ and $54.7 \pm 2.4 \mathrm{GPa}$, respectively). These results show that the AM1 agent contributed to increase the physicochemical interaction between the CF and the PP-PE matrix. This condition provided a better loading transfer from matrix to the reinforcement. Scanning electron microscopy analyses of the fracture surfaces show the fractographic aspects of the samples and allow evaluating the fiber/matrix-interfacial adhesion. Poor adhesion is observed for the CF/PP-PE and CF/PP-PE(AM2) laminates with the presence of fiber impressions on the polymer rich regions and fiber surfaces totally unprotected of polymer matrix. On the other side, a more consistent adhesion is observed for the CF/PP-PE(AM1) laminate. This result is in agreement with the tensile test data and show the presence of a good interaction between the laminate constituents. The correlation of the mechanical and fractographic results with the curves of complex viscosity versus temperature of the studied polymer matrices shows that the matrix viscosity did not affect the wettability of the reinforcement.
\end{abstract}

Keywords: fractography, thermoplastic composite, carbon fiber, PP-PE.

\section{Introduction}

The technological advances and the tight requirements demanded by aerospace, marine, automotive and sports equipment industries have promoted the increase employment of structural polymeric composite reinforced with carbon fibers in these areas. This trend is attributable to the low density $\left(1.4-1.6 \mathrm{~g} / \mathrm{cm}^{3}\right)$ of this class of materials associated with high values of both specific rigidity and mechanical resistance, characteristics that meet strict requirements in service. In addition, the processing of components with these materials is very versatile, capable of producing parts with large dimensions and complex shapes ${ }^{[1-5]}$.

In this context, thermosetting composites have been established in a prominent place in the structural materials area ${ }^{[6-10]}$. But more recently, the study and use of thermoplastic composites reinforced with continuous fibers in academic and industrial segments have increased, considering their high structural performance and similar or superior mechanical properties to those obtained with thermosetting composites. Beside this, they present high resistance to impact, better delamination resistance, and fracture toughness, greater resistance to environmental aging, they are non-flammable and can be stored for a long time at room temperature.
These characteristics have motivated the manufacture of components with applications in aerospace, automotive, oil, gas and civil infrastructure ${ }^{[11-13]}$.

In general, thermoplastic composites with continuous fibers are produced with less processing cycles, and can be hot pressed, thermoformed, pultruded, consolidated in autoclave or by automated methods on multiple complex shapes of large size ${ }^{[14-20]}$. Besides, they can be welded to other structures by electrical resistance, ultrasonic and induction technologies, for example ${ }^{[21-25]}$.

Despite the advantages provided by polymeric composite materials, defects and damages may be present in the laminated structure, caused by different variables, which may occur during the processing of the component or during its useful life. Defects can happen due to design errors or originated in various stages of manufacture (for example, during the laminate stacking sequence). The damages can be resulted of impacts from inadequate conditions of transport and storage or due to difficulties in operation ${ }^{[26-31]}$. Defects and damages, even if not noticeable on a visual inspection, can contribute significantly to the reduction of the composite's resistance. This situation can be aggravated when the 
composite is exposed to harsh environmental conditions such as sudden changes in temperature, high relative humidity and ultraviolet radiation, which can affect its mechanical properties and consequently its integrity and durability ${ }^{[32-35]}$.

Most of the structures manufactured in polymeric composites reinforced with continuous fibers are subjected to a diversity of loads. Accordingly, these structures are exposed to the occurrence of damages that may lead to the failure of material. Structural collapse may occur in different complicated shapes due to the anisotropic construction of the laminate, in which the possible failure modes to be developed are influenced by the orientation of fibers, number of layers, layer stacking sequence, load direction applied and environmental interactions.

The complete fracture of these materials typically occurs in three basic types, called: interlaminar, intralaminar and translaminar fractures, which generate fracture surfaces with different morphologies, consequently with different characteristics. When the fracture surfaces are properly interpreted, it is possible to identify the damage and failure processes. The fiber has influence on the matrix fracture process while the interfacial quality of fiber/matrix adhesion has a significant influence on the local where the failure starts. As consequence, the detailed fractographic analysis of fractured surfaces has fundamental importance on the qualitative evaluation of the processing-structure-property relationship of polymer composites. In this process it includes the analysis of resistance and loading conditions to which the material is subjected.

The fractography reveals the origin and the direction of crack propagation, the nature of loading that originated the crack, defects in material, failure mechanisms, and also determines the sequence of events of the failure and confirms or removes any suspicious on the failure modes present. Moreover, the fractography presents itself as a powerful research tool that generates information that supports the improvement of materials processing and encourages communication between experimental and predictive areas. This knowledge can be used in the development and evaluation of theoretical models of behavior and growth of cracks $^{[36-44]}$. Usually, the fractography is carried out with the aid of the scanning electron microscopy (SEM) technique.

The correct identification of fractographic aspects is not simple and immediate. However, if the fracture surface is accurately assessed, it is possible to identify and to analyze design data and composite processing parameters with potential to cause failures. This procedure is useful because it can be used to optimize the composite processing and also to prevent other damages that can occur in the future. Thus, fractographic studies have been strongly disseminated and used not only in the area of metallic materials, but also in the polymeric composites reinforced with continuous fibers $^{[45-53]}$.
Due to the steady increase of thermoplastic composite materials in the manufacturing industry of structural components, this work aims to contribute to the fractographic area of impregnated carbon fiber laminates with polypropylene/ polyethylene (PP-PE) copolymer, fractured in tensile loading at room temperature. Correlation of the observed fractographic aspects with both the used processing technique and the individual characteristics of the laminate components is made. A brief rheological study of the used thermoplastic matrices is presented and correlated with the microscopic observations.

\section{Materials and Methods}

\subsection{Materials}

In this study three different solid laminates were processed based on carbon fiber fabric $(\mathrm{CF})$ with orientation $\left(0^{\circ}, 90^{\circ}\right)$, style Plain Weave, with tows of 3000 filaments, from Hexcel Composites Co. This reinforcement was impregnated with thermoplastic matrices based on three PP-PE copolymer films, containing $7 \%$ (wt/wt) of ethylene monomer. Table 1 shows the specifications of the thermoplastic films used. Two of these films were modified by the manufacturer, Polibrasil Co., aiming to improve the mechanical behavior of the laminates reinforced with CF. For this, one of the PP-PE samples was modified with about $1 \%$ (wt/wt) of maleic anhydride. This sample was named PP-PE(AM1). The other sample was modified with $1 \%$ (wt/wt) of an elastomeric agent based on ethylene-octene copolymer, identified as AM2. Such elastomeric agent is used to improve the polymer flow and the impact resistance of PP-PE copolymers ${ }^{[54]}$.

The processing of the thermoplastic laminates was based on the hot compression molding technique. The $\mathrm{CF}$ reinforcing layers and the polymeric films were stacked on the mold surface, alternating one layer of CF and two layers of the polymeric film, in respective order, totaling 15 layers of $\mathrm{CF}$ and films. This proportion corresponds in the final laminate at approximately $60 \pm 1 \%$ by volume of CF. This value was determined by acid digestion, in triplicate, in accordance with ASTM D3171-11.

The hot compression molding was held in a hydraulic press, fitted with a mold of $400 \mathrm{~mm} \times 400 \mathrm{~mm}$. The heating rate was $2{ }^{\circ} \mathrm{C} / \mathrm{min}$ up to the maximum temperature of $230^{\circ} \mathrm{C}$, holding at this temperature for $2 \mathrm{~h}$. At this step, a pressure of $4 \mathrm{MPa}$ was applied. The cooling was natural until to reach the room temperature after $8 \mathrm{~h}$. This procedure ensured the consolidation of the laminates with a thickness of $3.0 \pm 0.1 \mathrm{~mm}$.

\subsection{Characterization}

From the processed laminates, specimens were prepared for the tensile mechanical tests, in a longitudinal direction, according to ASTM D3039/D3039M-00. For this, it was used

Table 1. Thermoplastic matrices used.

\begin{tabular}{ccc}
\hline Copolymer Matrices & Code & Melting Points ( ${ }^{\circ}$ C) \\
\hline PP-PE (with 7\% (wt/wt) of ethylene) & PP-PE & $128 / 163 \pm 0.5$ \\
PP-PE (with 7\% (wt/wt) of ethylene) + agent AM1 & PP-PE(AM1) & $126 / 164 \pm 0.5$ \\
PP-PE (with 7\% (wt/wt) of ethylene) + agent AM2 & PP-PE(AM2) & $126 / 164 \pm 0.5$ \\
\hline
\end{tabular}


an universal testing machine MTS- 810 model, at a constant speed of $2 \mathrm{~mm} / \mathrm{min}$ at room temperature. The specimens presented dimensions of $250 \mathrm{~mm} \times 25 \mathrm{~mm} \times 3 \mathrm{~mm}$ thickness, with tabs of CF/epoxy resin bonded with epoxy resin adhesive film at their ends. This procedure was adopted to distribute uniformly the clamping forces of the specimen in the grips of the testing machine, to favor the smooth transfer of the load to the specimen and to protect the laminate surface from possible damages during the test.

After the tensile tests, the specimens had the fracture surfaces protected with a tape and cut with a diamond disc. The fracture surfaces were cleaned blowing dry air to remove any possible cutting debris. Then, the surfaces were coated with a gold film by sputtering process, making them conductive for the SEM analyses in a microscope model FEI INSPECT S50.

In order to evaluate the influence of viscosity of the matrices on the $\mathrm{CF}$ impregnation, rheological analyses of PP-PE films were carried out using a rheometer HAAKE model RS6000, adapted with parallel plate geometry and a gap of $1 \mathrm{~mm}$. All films were heated up to $230{ }^{\circ} \mathrm{C}$ at a heating rate of $1{ }^{\circ} \mathrm{C} / \mathrm{min}$. Analyses were performed with tension of $500 \mathrm{~Pa}$. For this, previous analyses to identify the linear viscoelastic regime were made. The maximum temperature for these analyses was determined previously from thermogravimetric analyses in air, where the degradation temperatures varied between $240-245^{\circ} \mathrm{C}$.

\section{Results and Discussion}

When a laminate of polymeric matrix reinforced with continuous fibers is subjected to mechanical loading, the matrix begins to deform with the generation of strain on the fiber surface. As the reinforcement is sufficiently long, the load intensity necessary to lead them to fracture is higher, contributing to increase the composite strength. However, the conditions for an effective transfer of efforts from the matrix to the fibers depend on the nature of the fiber/matrix interface. Thus, the interface characteristics formed between the reinforcement and the polymer matrix have a great importance on the structural performance of the laminate, affecting the mechanical properties and the failure process of the composite.

Table 2 shows the results of strength and elasticity modulus in tensile of the bidirectional laminates $\left(0^{\circ}, 90^{\circ}\right)$ tested in longitudinal direction. The analysis of this table shows that the CF/PP-PE(AM1) laminate presents higher tensile strength $(507.6 \pm 11.8 \mathrm{MPa})$, followed by CF/PP-PE and CF/PP-PE(AM2) laminates, with mean resistance values of $440.1 \pm 35.9 \mathrm{MPa}$ and $422.8 \pm 27.9 \mathrm{MPa}$, respectively. The correlation of these data shows that the

Table 2. Results of strength and elastic modulus in tensile of the laminates.

\begin{tabular}{ccc}
\hline Composite & $\begin{array}{c}\text { Tensile Strength } \\
\text { (MPa) }\end{array}$ & $\begin{array}{c}\text { Elastic Modulus } \\
\text { (GPa) }\end{array}$ \\
\hline CF/PP-PE & $440.1 \pm 35.9$ & $37.4 \pm 3.4$ \\
CF/PP-PE(AM1) & $507.6 \pm 11.8$ & $54.7 \pm 2.4$ \\
CF/PP-PE(AM2) & $422.8 \pm 27.9$ & $48.6 \pm 5.7$ \\
\hline
\end{tabular}

AM1 agent contributed to have a more resistant laminate, about 15\% higher than that determined for the CF/PP-PE. This behavior is attributed to the AM1 agent that improved the interaction between $\mathrm{CF}$ reinforcement and the polymer matrix. In this case, the AM1 agent contributed to increase the effort transference from the matrix to the fibers. On the other hand, the CF/PP-PE(AM2) laminate provides a lower mean value of tensile strength than that determined for the CF/PP-PE laminate, around $4 \%$ lower. This indicates that the AM2 agent did not favor the formation of a stronger reinforcement/matrix interface. However, considering the standard deviations of these measures it is possible to conclude, in a general way, that the film with the AM2 agent did not affect the tensile strength of the CF/PP-PE(AM2) laminate in relation to the CF/PP-PE one.

Regarding the elastic modulus results it is observed a descending order, where the best result was achieved for the CF/PP-PE(AM1) laminate $(54.7 \pm 2.4 \mathrm{GPa})$, followed by CF/PP-PE(AM2) $(48.6 \pm 5.7 \mathrm{GPa})$ and $\mathrm{CF} / \mathrm{PP}-\mathrm{PE}$ $(37.4 \pm 3.4 \mathrm{GPa})$ laminates. These results reinforce that the CF/PP-PE(AM1) laminate shows the best mechanical behavior in tensile, evidencing that the AM1 agent provided greater chemical compatibility between the components, the PP-PE matrix and CF reinforcement. Probably, the existence of the largest chemical affinity conferred by maleic anhydride in the PP-PE polymer matrix assured a better interfacial adhesion fiber/polymeric matrix, which influenced positively the laminate strength. The results indicate also that the use of AM2 modifying agent, containing an elastomeric phase, increased the deformation stress of the laminate, in relation to the CF/PP-PE laminate.

The processing windows of polymers and their composites can be determined from the behavior of the complex viscosity curve $\left(\eta^{*}\right)$ versus temperature or time. Figure 1 shows the complex viscosity graphic versus temperature of PP-PE, PP-PE(AM1) and PP-PE(AM2) films. As expected, Figure 1 shows that the viscosities of all films decrease with the temperature increasing. This behavior is due to the gradual destruction of existing interaction forces (van der Waals forces) with the temperature increasing.

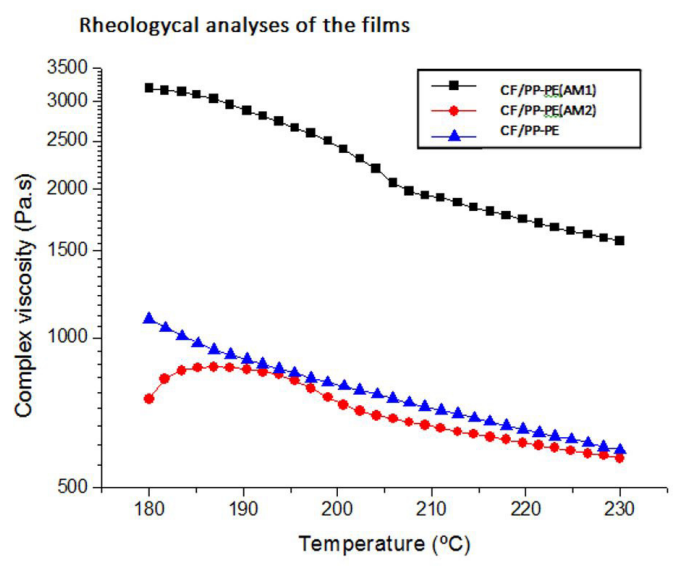

Figure 1. Complex viscosity curves versus temperature of PP-PE films. 
This structure can also be destroyed with the shear rate increasing. The PP-PE(AM1) film presents higher viscosity values ranging from 1600 to $3100 \mathrm{~Pa}$.s, in the temperature range used in the analysis $\left(180\right.$ to $\left.230^{\circ} \mathrm{C}\right)$. These higher viscosity values can be attributed to the presence of maleic anhydride, which favored coupling reactions with the polyolefin, resulting in the viscosity increase and, possibly, the molar mass increase of the copolymer ${ }^{[55]}$. For this sample, it can also be observed the presence of a curve between 180 and $200{ }^{\circ} \mathrm{C}$. This behavior evidences the action of maleic anhydride on the rheological behavior of the PP-PE in function of temperature.

The matrices of PP-PE and PP-PE(AM2) present the complex viscosity curves very close, with viscosity values ranging from 550 to $1100 \mathrm{~Pa}$.s, in the temperature range between 180 and $230{ }^{\circ} \mathrm{C}$. However, the PP-PE viscosity behavior presents a continuous drop in all temperature range, while the viscosity of the PP-PE(AM2), in the range of 180 to $200{ }^{\circ} \mathrm{C}$, shows a sharp curve during the fall of viscosity, highlighting the AM2 agent behavior in this sample. The decrease of the viscosity of PE-PP(AM2) sample due to the elastomeric compatibilizer addition resulted in improved fluidity, in accordance with literature ${ }^{[54]}$.

Figures 2-5 show representative images of the fracture surfaces resulted from the tensile tests of the studied laminates. In this case, SEM analyses contributed to the observations and the capture of images of the fracture surfaces. The observed aspects were identified and correlated with the medium values of tensile strength, determined for each laminate studied.

The failure in tensile is one of the easiest failure modes to be found and understood in composite materials and has long been studied by many authors ${ }^{[42-44]}$. Generally, the fracture follows the development and propagation of cracks through the matrix and the fiber/polymeric matrix interface, because of the stress concentration in the material produced. Figure 2 shows detailed images of $\mathrm{CF}$, obtained on the fracture surface of CF/PP-PE specimens tested in tensile. Figure 2a shows the longitudinal section of a $\mathrm{CF}$, with typical superficial grooves of this type of reinforcement. This observed aspects is inherited from the polymeric precursor, polyacrylonitrile (PAN) fiber, as cited in the literature ${ }^{[56,57]}$.

In this particular case, the $\mathrm{CF}$ image shows that this region presents a poor interfacial adhesion between fiber/matrix. This observation can be attributed to the poor interaction of the components or due to the incomplete percolation of the polymeric matrix into the reinforcement. The considerable plastic deformation observed on the fracture surface allows characterizing the polymeric matrix as thermoplastic type, independent of previous information about the polymeric
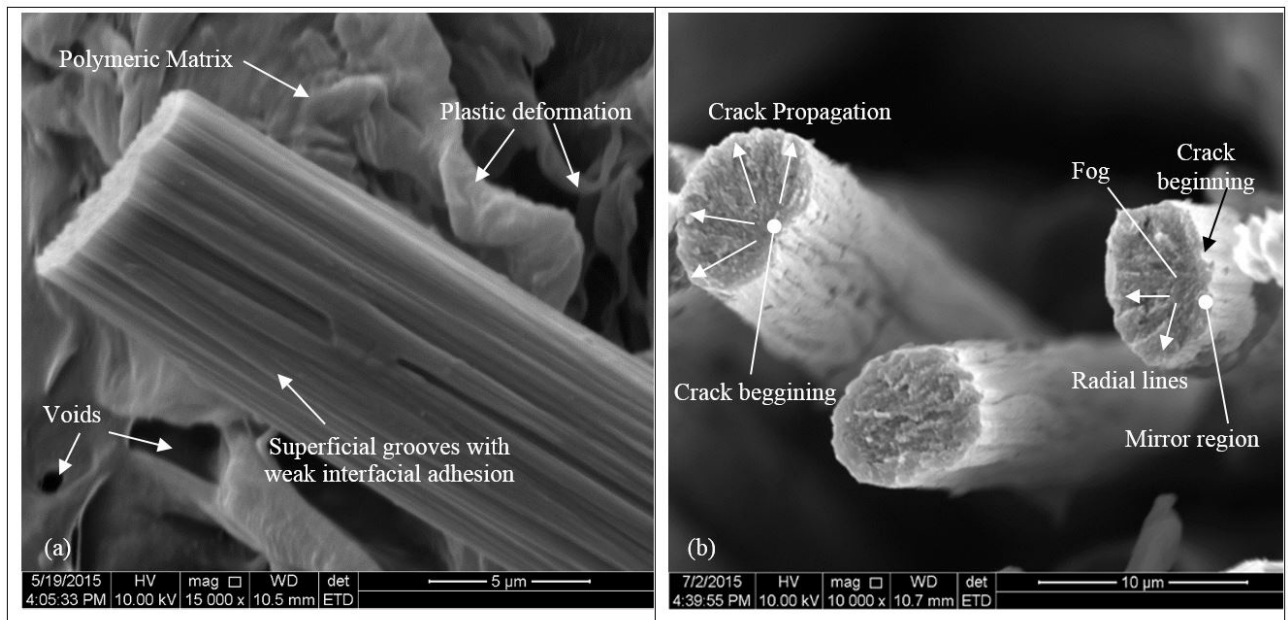

Figure 2. Fractographic aspects of longitudinal section of $\mathrm{CF}$ (a) and fractured surface (CF top) representative of the CF/PP-PE(AM2) and $\mathrm{CF} / \mathrm{PP}-\mathrm{PE}$ laminates (b), respectively, tested in tensile.
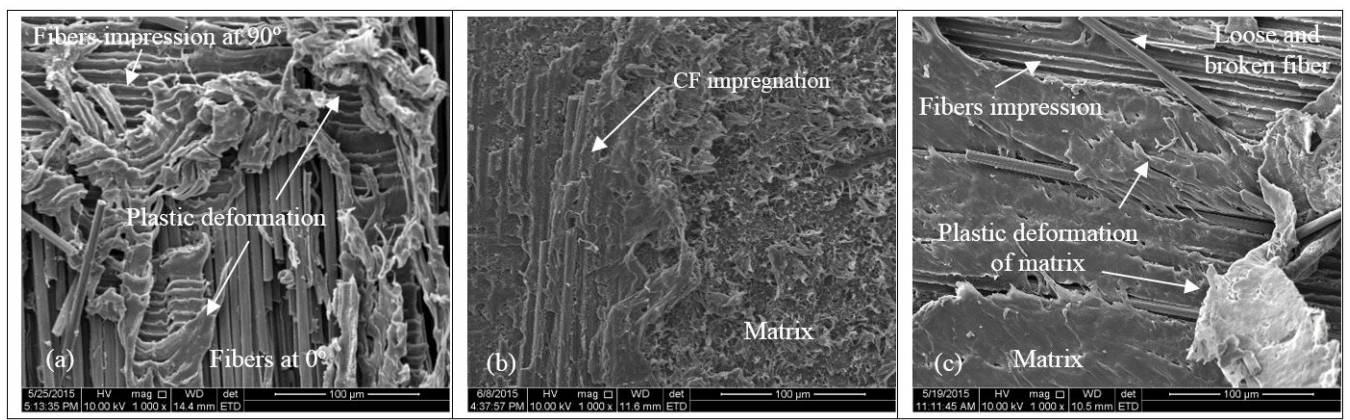

Figure 3. Details of the fracture topography of CF/PP-PE (a), CF/PP-PE(AM1) (b) and CF/PP-PE(AM2) (c) laminates. 

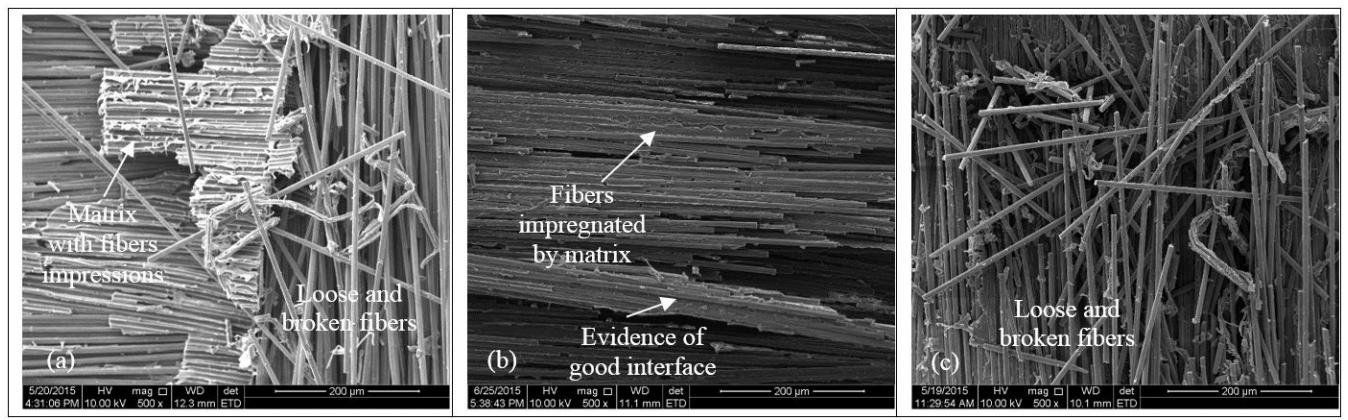

Figure 4. Partial views of CF/PP-PE (a), CF/PP-PE(AM1) (b) and CF/PP-PE(AM2) (c), with emphasis on reinforcement rich regions.
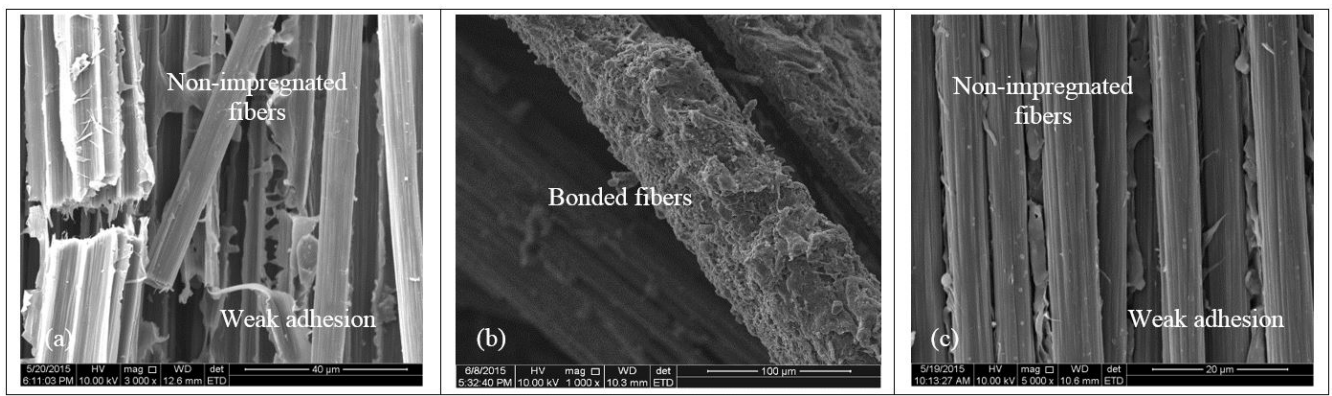

Figure 5. Details of impregnation of CF/PP-PE (a), CF/PP-PE(AM1) (b) and CF/PP-PE(AM2) (c).

matrix used in composite processing. It is also observed the presence of small voids dispersed within the matrix. Generally, in thermoplastic composites, voids are nucleated at lower stress levels, and they are often developed in the fiber/matrix interface. With the continuing loading, the voids grow with the plastic deformation and viscoelastic behavior of the matrix, clumping together to form the fracture surface of the tested laminate ${ }^{[44]}$.

Figure $2 \mathrm{~b}$ shows another typical detail of CF laminates tested in tensile, which presents the end sections of three isolated carbon fiber filaments fractured, without the impregnation of polymer matrix. The identified fractographic aspects are highlighted by arrows on the fracture surface of each fiber. Apparently, the failure beginning on the fiber is caused by the presence of a small defect in the fiber itself or in the fiber/matrix interface. Immediately next to the failure start point area, there is a fracture surface relatively flat, termed as mirror region, which indicates a slow fracture, in which there is only enough energy to propagate the crack. However, from the time that the fracture starts to propagate, the fracture velocity increases and the fracture topography becomes more rugged and rough with the fog aspect, forming radial line marks on the fiber surface. Radial lines present the aspect of an open range from an origin point. This aspect is often found on CF fracture surfaces. This aspect is considered relevant in the failure analysis of continuous fibers reinforced polymer composites, subjected to tensile stress and helps in the crack growth direction mapping. Similar aspects are reported in the literature ${ }^{[44]}$.

Figure 3 shows representative images of the three thermoplastic laminates failed by delamination. Unlike of the fractographic aspects observed in thermoset composites, where the fractographic aspects are more easily identified and explained ${ }^{[36,38,44]}$, the fractographic evaluation of thermoplastic composites is much more complex. The more difficulty is due to the fact of thermoplastic matrices present few fractographic aspects due to their viscoelastic nature that generates deformations continuously during the application of mechanical loading. Thus, the investigator must know very well the characteristics of the individual components and the used processing technique in order to extract information from a complex and little elucidative scenario.

Despite this, Figure 3 shows that the three PP-PE laminates present different fracture morphologies, attributed to the modifying agents used in PP-PE films (Table 1). The $\mathrm{CF} / \mathrm{PP}-\mathrm{PE}$ laminate (Figure $3 \mathrm{a}$ ), when compared to the other laminates, presents the worst impregnation, revealing regions of fiber oriented at $0^{\circ}$ fully exposed, i.e., without impregnation of the polymer matrix. It is also observed extensive regions of polymer matrix positioned between $\mathrm{CF}$ fabric layers. These polymer rich regions show significant plastic deformation, as indicated by the fiber impressions at $90^{\circ}$, which are formed from the interlaminar failure propagation during the mechanical loading. The presence of these fractographic aspects on the fracture surface shows the weak interfacial adhesion fiber/matrix. It is also observed that the fracture plane of laminate presents broken fibers at $0^{\circ}$, occurred at various levels due to insufficient percolation of the polymer matrix into the reinforcement and poor fiber/ matrix adhesion.

Figure $3 \mathrm{~b}$ shows a fractured region of CF/PP-PE(AM1) laminate. This figure shows a region with good consolidation, where the thermoplastic matrix is more cohesive and with aspects partially smooth and rough simultaneously. 
In this case, it is observed that the reinforcement is better incorporated into the matrix, i.e., the $\mathrm{CF}$ is more impregnated by the polymeric matrix. These features indicate that the laminate presents an interface fiber/matrix stronger than that observed in Figure 3a. Figure 3c shows fractographic aspects identified in the region failed by delamination of the CF/PP-PE(AM2) laminate. Fiber impressions on the matrix and some loose fibers suggest the existence of a weak adhesion in the fiber/matrix interface, as noted in the CF/PP-PE laminate (Figure 3a). However, in this case, the polymer matrix presents extensive regions with smoother texture, different from that observed in the other two laminates. Probably, the manifestation of this feature was influenced by the elastomeric agent AM2 used the PP-PE(AM2) composition (Table 1).

Figure 4 shows images taken with smaller magnifications of regions with partial views of the CF reinforcement. This figure shows clearly the presence of loose and broken $\mathrm{CF}$, Figure $4 \mathrm{a}$ and Figure $4 \mathrm{c}$, relative to $\mathrm{CF} / \mathrm{PP}-\mathrm{PE}$ and $\mathrm{CF} / \mathrm{PP}-\mathrm{PE}(\mathrm{AM} 2)$ laminates, respectively. In Figure 4a are observed matrix rich regions, presenting loose matrix layers with fibers impression, adjacent to the fracture plane. These observations confirm the weak interfacial adhesion between the components of CF/PP-PE laminate. In Figure 4c, the fibers are unprotected of matrix, misaligned and with many fragments of matrix on the surface. These evidences show weak interfacial adhesion and also the probably occurrence of problems in the composite processing stages.

Figure $4 \mathrm{~b}$ shows the $\mathrm{CF}$ bonded to the polymeric matrix, indicating the wetting of the reinforcement by the matrix and therefore a better consolidation, with more consistent interface between the components of the composite. The presence of broken fibers in different sizes impregnated by the matrix consists of a fractographic aspect that indicates that the laminate failed at different stress levels with the applied load increasing. This behavior is further evidence that the use of AM1 coupling agent improved the reinforcement/matrix interaction, in relation to the other two laminates. This suggests a better interfacial adhesion, which provided a greater tensile strength as compared with PP-PE and PP-PE(AM2) laminates (Table 2).

In the hot compression molding of composites is essential the complete percolation of the polymer matrix among the reinforcing layers. This condition provides bonding of the fibers and a good consolidation of the laminate structure with orderly and consistent interfacial adherence of fiber/matrix. Figure 5 shows a comparison of the impregnating features observed in the laminates studied. It is evident that the laminate CF/PP-PE(AM1) presents a much more efficient impregnation of the reinforcement (Figure 5b), than the other two laminates (Figure 5a and Figure 5c). In Figure 5a,c are observed misaligned fibers without impregnation, emphasizing the weak interfacial adhesion. These observations can be attributed to variations in the composite molding process, including difficulty in the matrix flow, which may prejudice the wetting and interactions between polymer and reinforcing under the actions of temperature and pressure. The matrix texture appearance, shown in Figure 5b, suggests that the fibers wetting quality promoted by the PP-PE(AM1) matrix increased the physicochemical contact between the composite components.
The correlation of SEM observations with the tensile strength results presented in Table 2 is consistent. This correlation shows that the CF/PP-PE(AM1) laminate has better impregnation of the reinforcement and the highest value of both tensile strength $(507.6 \pm 11.8 \mathrm{MPa})$ and elastic modulus $(54.7 \pm 2.4 \mathrm{GPa})$, when compared to the other two laminates. The main influence of weak interfacial adhesion is the reduction of the mechanical properties, which compromises the final application of the composite.

The comparison of SEM observations with the rheological curves of the polymer matrices (Figure 1) shows that the greatest viscosity values of the PP-PE(AM1) matrix did not affect the wetting of the reinforcement. In this case, the processed laminate presents the best impregnation and the best mechanical performance. This result shows that the AM1 agent (maleic anhydride) acts as a good coupling agent, increasing the polarity of the PP-PE matrix and improving the reinforcement/matrix interaction. The efficiency of using the maleic anhydride as compatibilizing of copolymers and blends, aiming to improve adhesion and hydrophobicity of polyolefins, has been widely reported in literature ${ }^{[55,58]}$. Therefore, the interface feature has significant influence on both mechanical behavior and failure process of tensile tested-specimens.

\section{Conclusions}

In the present work, the morphological aspects and tensile mechanical properties of CF/PP-PE laminates, with three different compositions of the PP-PE, were investigated. Two PP-PE matrices were modified with the agents designated AM1 (maleic anhydride) and AM2 (elastomeric agent). The CF/PP-PE(AM1) laminate showed the best tensile strength result $(507.6 \pm 11.8 \mathrm{MPa})$. While the $\mathrm{CF} / \mathrm{PP}-\mathrm{PE}(\mathrm{AM} 2)$ presented a reduction in strength at around $4 \%(422.8 \pm 27.9 \mathrm{MPa})$ compared to CF/PP-PE $(440.1 \pm 35.9 \mathrm{MPa})$. Similarly, the highest elastic modulus values were determined for the CF/PP-PE(AM1) $(54.7 \pm 2.4 \mathrm{GPa})$, followed by the CF/PP-PE(AM2) $(48.6 \pm 5.7 \mathrm{GPa})$ and CF/PP-PE $(37.4 \pm 3.4 \mathrm{GPa})$ laminates. These results show that the incorporation of AM1 agent in the PP-PE film contributed to increase the physicochemical interaction fiber/matrix and provided better conditions for the charge transference between matrix and reinforcement. Fractographic analyses of the CF/PP-PE laminate shows poor adhesion between fiber and polymer matrix. This aspect was indicated by the presence of fiber impressions in polymer rich regions and CF surfaces totally non-impregnated by polymer matrix. The most consistent adhesion was observed for the CF/PP-PE(AM1) laminate, in accordance with the best mechanical performance in tensile. Plastic deformations are identified in the fracture morphology of the polymer rich regions attributed to the viscoelastic behavior of thermoplastic matrix. Other fractographic aspects, such as radial line marks, are observed in the fracture surface of the fibers oriented at $0^{\circ}$. Areas with significant volume of fiber non-impregnated suggest possible problems in the composite molding process. Complex viscosity results showed that this parameter did not influence the wetting of the carbon fiber reinforcement. 


\section{Acknowledgements}

The authors thank CNPq for the financial supports (Process numbers: 150697/2014-7, 142314/2010-2 and 303287/2013-6) and CAPES/PVNS.

\section{References}

1. Feraboli, P., \& Masini, A. (2004). Development of carbon/ epoxy structural components for a high performance vehicle. Composites. Part B, Engineering, 35(4), 323-330. http://dx.doi. org/10.1016/j.compositesb.2003.11.010.

2. Edwards, K. L. (2004). Exploiting new materials and processes for higher productivity: use of advanced composite technologies. Materials \& Design, 25(7), 565-571. http://dx.doi.org/10.1016/j. matdes.2004.02.016.

3. Soutis, C. (2005). Fiber reinforced composites in aircraft construction. Progress in Aerospace Sciences, 41(2), 143-151. http://dx.doi.org/10.1016/j.paerosci.2005.02.004.

4. Roeseler, W. G., Sarh, B., \& Kismarton, M. U. (2007). Composite structures: the first 100 years. In Proceedings of the ICCM-16 Sixteenth International Conference on Composite Materials (pp. 1-10). Kyoto: ICCM.

5. Savage, G. (2010). Formula 1 composites engineering. Engineering Failure Analysis, 17(1), 92-115. http://dx.doi. org/10.1016/j.engfailanal.2009.04.014.

6. Mrzova, M. (2013). Advanced composite materials of the future in aerospace industry. Incas Bulletin, 5(3), 139-150. http://dx.doi.org/10.13111/2066-8201.2013.5.3.14.

7. Friedrich, K., \& Almajid, A. A. (2013). Manufacturing aspects of advanced polymer composites for automotive applications. Applied Composite Materials, 20(2), 107-128. http://dx.doi. org/10.1007/s10443-012-9258-7.

8. Ren, Y., Xiang, J., \& Zheng, J. (2015). The crashworthiness design of transport aircraft using composite structure. In Proceedings of the 20th International Conference on Composite Materials. Copenhagen: ICCM.

9. Kako, J. C., \& Roth, Y. C. (2015). Applications and challenges of prepreg forming technologies in aircraft industry. In Proceedings of the 20th International Conference on Composite Materials. Copenhagen: ICCM.

10. Martensson, P., Zenkert, D., \& Akermo, M. (2015). The effects of cost and weight efficient structural design for manufacturing of composite automotive body structures. In Proceedings of the 20th International Conference on Composite Materials. Copenhagen: ICCM.

11. Luinge, J. W. (2015). Thermoplastic composites: material developments for aerospace applications, incorporation of a functional tie layer. In Proceedings of the 20th International Conference on Composite Materials. Copenhagen: ICCM.

12. Nakai, A., Uozumi, T., Ohtani, A., Kanamori, T., \& Nagoh, S. (2015). High-cycle molding of continuous fiber reinforced thermoplastic composite pipe. In Proceedings of the 20th International Conference on Composite Materials. Copenhagen.

13. Arhant, M., Davies, P., Burtin, C., \& Briançon, C. (2015). Thermoplastic matrix composites for underwater applications. In Proceedings of the 20th International Conference on Composite Materials. Copenhagen: ICCM.

14. Nogueira, C. L., Marlet, J. M. F., \& Rezende, M. C. (1999). Processo de obtenção de pré-impregnados poliméricos termoplásticos via moldagem por compressão a quente. Polímeros: Ciência e Tecnologia, 9(3), 18-27. http://dx.doi. org/10.1590/S0104-14281999000300006.

15. Novo, P. J., Silva, J. F., Nunes, J. P., \& Marques, A. T. (2015). Advances in thermoplastic pultruded composites. In Proceedings of the 20th International Conference on Composite Materials. Copenhagen: ICCM.
16. Schäfer, J., Gries, T., Schuster, R., \& Lammel, C. (2015). Continuous production of fibre reinforced thermoplastic composites by braiding pultrusion. In Proceedings of the 20th International Conference on Composite Materials. Copenhagen: ICCM.

17. Hoang, M. D., Simpson, J. F., \& Hoa, S. V. (2015). Mechanical properties of thermoplastic composites made by automated fiber placement. In Proceedings of the 20th International Conference on Composite Materials. Copenhagen: ICCM.

18. Rodríguez-Lence, F., Zuazo, M., \& Calvo, S. (2015). In-situ consolidation of PEEK composites by automated placement technologies. In Proceedings of the 20th International Conference on Composite Materials. Copenhagen: ICCM.

19. Fernández, I., Blas, F., \& Frövel, M. (2003). Autoclave forming of thermoplastic composite parts. Journal of Materials Processing Technology, 143-144, 266-269. http://dx.doi.org/10.1016/ S0924-0136(03)00309-1.

20. Marques, L. S., Narita, N. E., Costa, G. C., \& Rezende, M. C. (2010). Avaliação dos comportamentos mecânico e térmico de laminados de PPS/fibra de carbono processados em autoclave sob diferentes ciclos de consolidação. Polímeros: Ciência e Tecnologia, 20(4), 309-314. http://dx.doi.org/10.1590/S010414282010005000043.

21. Stavrov, D., \& Bersee, H. E. N. (2005). Resistance welding of thermoplastic composites-an overview. Composites. Part A, Applied Science and Manufacturing, 36(1), 39-54. http:// dx.doi.org/10.1016/S1359-835X(04)00182-4.

22. Ahmed, T. J., Stavrov, D., Bersee, H. E. N., \& Beukers, A. (2006). Induction welding of thermoplastic composites-an overview. Composites. Part A, Applied Science and Manufacturing, 37(10), 1638-1651. http://dx.doi.org/10.1016/j.compositesa.2005.10.009.

23. Dubé, M., Hubert, P., Yousefpour, A., \& Denault, J. (2007). Resistence welding of thermoplastic composites skin/ stringer joints. Composites. Part A, Applied Science and Manufacturing, 38(12), 2541-2552. http://dx.doi.org/10.1016/j. compositesa.2007.07.014.

24. Costa, A. P., Botelho, E. C., Costa, M. L., Narita, N. E., \& Tarpani, J. R. (2012). A review of welding technologies for thermoplastic composites in aerospace applications. Journal of Aerospace Technology and Management, 4(3), 255-265. http://dx.doi.org/10.5028/jatm.2012.040303912.

25. Villegas, I. F. (2014). Strength development versus process data in ultrasonic welding of thermoplastic composites with flat energy directors and its application to the definition of optimum processing parameters. Composites. Part A, Applied Science and Manufacturing, 65, 27-37. http://dx.doi.org/10.1016/j. compositesa.2014.05.019.

26. Almeida, S. F. M., \& Nogueira, Z. S., No. (1994). Effect of void content on the strength of composite laminates. Composite Structures, 28(2), 139-148. http://dx.doi.org/10.1016/02638223(94)90044-2.

27. Zhu, H., Wu, B., Li, D., Zhang, D., \& Chen, Y. (2011). Influence of voids on the tensile performance of carbon/epoxy fabric laminates. Journal of Materials Science and Technology, 27(1), 69-73. http://dx.doi.org/10.1016/S1005-0302(11)60028-5.

28. Scott, A. E., Sinclair, I., Spearing, S. M., Mavrogordato, M. N., \& Hepples, W. (2014). Influence of voids on damage mechanisms in carbon/epoxy composites determined via high resolution computed tomography. Composites Science and Technology, 90, 147-153. http://dx.doi.org/10.1016/j. compscitech.2013.11.004.

29. Liebig, W. V., Viets, C., Schulte, K., \& Fiedler, B. (2015). Influence of voids on the compressive failure behaviour of fibrereinforced composites. Composites Science and Technology, 117, 225-233. http://dx.doi.org/10.1016/j.compscitech.2015.06.020.

30. Matadi Boumbimba, R., Froustey, C., Viot, P., \& Gerard, P. (2015). Low velocity impact response and damage of laminate 
composite glass fibre/epoxy based tri-block copolymer. Composites. Part B, Engineering, 76, 332-342. http://dx.doi. org/10.1016/j.compositesb.2015.02.007.

31. Liang, Y., Wang, H., Soutis, C., Lowe, T., \& Cernik, R. (2015). Progressive damage in satin weave carbon/epoxy composites under quasi-static punch-shear loading. Polymer Testing, 41, 82-91. http://dx.doi.org/10.1016/j.polymertesting.2014.10.013.

32. Costa, M. L., Rezende, M. C., \& Almeida, S. F. M. (2005). Strength of hygrothermally conditioned polymer composites with voids. Journal of Composite Materials, 39(21), 1943-1961. http://dx.doi.org/10.1177/0021998305051807.

33. Mouzakis, D. E., Zoga, H., \& Galiotis, C. (2008). Accelerated environmental ageing study of polyester/glass fiber reinforced composites (GFRPCs). Composites. Part B, Engineering, 39(3), 467-475. http://dx.doi.org/10.1016/j.compositesb.2006.10.004.

34. Zhong, Y., \& Joshi, S. C. (2015). Impact behavior and damage characteristics of hygrothermally conditioned carbon epoxy composite laminates. Materials \& Design, 65, 254-264. http:// dx.doi.org/10.1016/j.matdes.2014.09.030

35. Sethi, S., \& Ray, B. C. (2015). Environmental effects on fibre reinforced polymeric composites: evolving reasons and remarks on interfacial strength and stability. Advances in Colloid and Interface Science, 217, 43-67. PMid:25578406. http://dx.doi. org/10.1016/j.cis.2014.12.005.

36. Purslow, D. (1981). Some fundamental aspects of composites fractography. Composites, 12(4), 241-247. http://dx.doi. org/10.1016/0010-4361(81)90012-4.

37. Purslow, D. (1984). Composites fractography without an SEM - the failure analysis of a CRFP I-beam. Composites, 15(1), 43-48. http://dx.doi.org/10.1016/0010-4361(84)90960-1.

38. Purslow, D. (1986). Matrix fractography of fibre-reinforced epoxy composites. Composites, 17(4), 289-303. http://dx.doi. org/10.1016/0010-4361(86)90746-9.

39. Purslow, D. (1987). Matrix fractography of fibre-reinforced thermoplastics, Part 1. Peel failures. Composites, 18(5), 365374. http://dx.doi.org/10.1016/0010-4361(87)90360-0.

40. Purslow, D. (1988). Matrix fractography of fibre-reinforced thermoplastics, Part 2. Shear failures. Composites, 19(2), 115-125. http://dx.doi.org/10.1016/0010-4361(88)90721-5.

41. Purslow, D. (1988). Matrix fractography of fibre-reinforced thermoplastics, Part 3. Tensile, compressive and flexure failures. Composites, 19(5), 358-366. http://dx.doi.org/10.1016/00104361(88)90123-1.

42. Roulin-Moloney, A. C. (1989). Fractography and failure mechanisms of polymers and composites. England: Elsevier Science Publishers.

43. Miracle, D. B., \& Donaldson, S. (2001). ASM Handbook: composites (Vol. 21). Materials Park: ASM International.

44. Greenhalgh, E. (2009). Failure analysis and fractography of polymer composites. Cambridge: Woodhead Publishing Limited.

45. Rezende, M. C. (2007). Fractografia de compósitos estruturais. Polímeros: Ciência e Tecnologia, 17(3), E4-E11. http://dx.doi. org/10.1590/S0104-14282007000300003.

46. Franco, L. A. L., Graça, M. L. A., \& Silva, F. S. (2008). Fractography analysis and fatigue of thermoplastic composite laminates at different environmental conditions. Materials Science and Engineering A, 488(1-2), 505-513. http://dx.doi. org/10.1016/j.msea.2007.11.053.
47. Bonhomme, J., Argüelles, A., Vinã, J., \& Vinã, I. (2009). Fractography and failure mechanisms in static mode I and mode II delamination testing of unidirectional carbon reinforced composites. Polymer Testing, 28(6), 612-617. http://dx.doi. org/10.1016/j.polymertesting.2009.05.003.

48. Vinod, M. S., Sunil, B. J., Nayaka, V., Shenoy, R., Murali, M. S., \& Nafidi, A. (2010). Fractography of compression failed carbon fiber reinforced plastic composite laminates. Journal of Mechanical Engineering Research, 2(1), 1-9. Retrieved in 18 August 2015, from http://www.academicjournals.org/ article/article1379601327_Vinod\%20et\%20al.pdf.

49. Kumar, M. S., Raghavendra, K., Venkataswamy, M. A., \& Ramachandra, H. V. (2012). Fractographic analysis of tensile failures of aerospace grade composites. Materials Research, 15(6), 990-997. http://dx.doi.org/10.1590/S151614392012005000141.

50. Cândido, G. M., Donadon, M. V., Almeida, S. F. M., \& Rezende, M. C. (2012). Fractografia de compósito estrutural aeronáutico submetido à caracterização de tenacidade à fratura interlaminar em modo I. Polímeros: Ciência e Tecnologia, 22(1), 41-53. http://dx.doi.org/10.1590/S0104-14282012005000019.

51. Cândido, G. M., Fernandes, J. C., \& Rezende, M. C. (2013). Análise fractográfica de defeitos identificados na morfologia de fratura de compósitos poliméricos de fibras contínuas. In Anais do $12^{\circ}$ Congresso Brasileiro de Polímeros $\left(12^{\circ} \mathrm{CBPol}\right)$. Florianópolis: CBPOL.

52. Cândido, G. M., Mazur, R. L., Botelho, E. C., \& Rezende, M. C. (2013). Estudo fractográfico do compósito termoplástico de carbono/PEKK ensaiado de carregamento de tração. In Anais do $12^{\circ}$ Congresso Brasileiro de Polímeros $\left(12^{\circ} \mathrm{CBPol}\right)$. Florianópolis: $\mathrm{CBPOL}$.

53. Cândido, G. M., Donadon, M. V., Almeida, S. F. M., \& Rezende, M. C. (2014). Fractografia de compósito estrutural aeronáutico submetido ao ensaio de tenacidade à fratura interlaminar em modo II. Polímeros: Ciência e Tecnologia, 24(1), 65-71. http:// dx.doi.org/10.4322/polimeros.2013.008.

54. UL Prospector. (2015). Retrieved in 18 August 2015, from http:// plastics.ulprospector.com/pt/datasheet/e30953/engage-8180

55. Maurano, C. H. F., Galland, G. B., \& Mauler, R. S. (1998). Influência da estrutura de diferentes copolímeros de etileno e a-olefinas na funcionalização com anidrido maleico. Polímeros: Ciência e Tecnologia, 8(3), 79-88. http://dx.doi.org/10.1590/ S0104-14281998000300011.

56. Levy, F., No., \& Pardini, L. C. (2006). Reforços para compósitos. In F. Levy No., \& Pardini, L. C. Compósitos estruturais: ciência e tecnologia (pp. 59-106). São Paulo: Edgard Bücher.

57. Marinucci, G. (2011). Fibras. In G. Marinucci Materiais compósitos poliméricos: fundamentos e tecnologia (pp. 63-78). São Paulo: Artliber.

58. Lu, B., \& Chung, T. C. (2000). Synthesis of maleic anhydride grafted polyethylene and polypropylene, with controlled molecular structures. Journal of Polymer Science. Part A, Polymer Chemistry, 38(8), 1337-1343. http://dx.doi. org/10.1002/(SICI)1099-0518(20000415)38:8<1337::AIDPOLA18>3.0.CO;2-8. 